\title{
Finite Element Stress Analysis of Indirect Restorations Prepared in Cavity Bases
}

\author{
Takatsugu YAMAMOTO${ }^{1}$, Shinichi TAKEISHI ${ }^{2}$ and Yasuko MOMOI ${ }^{1}$ \\ ${ }^{1}$ Department of Operative Dentistry, Tsurumi University School of Dental Medicine, 2-1-3, Tsurumi, Tsurumi-ku, Yokohama, \\ Kanagawa 230-8501, Japan \\ ${ }^{2} \mathrm{CAE}$ Team, Digital Engineering Group, Engineering Department, Fuji Techno Service, 974-1, Aikou, Atsugi, Kanagawa 243- \\ 0035, Japan \\ Corresponding author, Takatsugu YAMAMOTO; E-mail: yamamoto-tk@tsurumi-u.ac.jp
}

Received February 24, 2006 /Accepted December 5, 2006

The objective of this study was to analyze the distribution of tensile stresses in indirect restorations prepared in several composite cavity bases. Elastic moduli of 20 materials were measured by nanoindentation technique for finite element analysis. Axisymmetric models of posterior onlays were constructed using combinations of two onlay materials and three cavity base materials. Thickness of resin cement was $50 \mu \mathrm{m}$. A vertical load of $95.5 \mathrm{~N}$ was applied on the cusp tip. Maximum stress of $18.1 \mathrm{MPa}$ was found in the model consisting of a ceramic onlay and a flowable resin composite base. It was also found that tensile stress increased as the area of the base having a lower elastic modulus became wider. Base materials having higher elastic moduli were determined to be suitable as cavity base materials for posterior restorations.

Keywords: Finite element analysis, Indirect restoration, Cavity base

\section{INTRODUCTION}

Rapid advances in enamel and dentin adhesive technology have significantly changed the landscape of caries treatment. Since the establishment of procedures for minimal caries removal and adhesive resin composite restorations ${ }^{1}$, adhesion has played an unequivocally pivotal role in minimal intervention dentistry $^{2,3)}$. As a result, numerous dental polymeric materials have been developed, such that direct adhesive restorations have performed well in many clinical cases which used to be restored indirectly.

However, while techniques for minimizing tooth reduction has been utilized by and therefore benefited direct adhesive restorations ${ }^{3,4}$, this is not the optimistic case with indirect restorations-despite the emergence of many adhesive materials, such as resin cements. As a result, conventional indirect restorative procedures, which result in excessive tooth reduction, continue to be performed clinically. For example, in the case of a secondary caries at the gingival margin on the proximal surface of a Class II inlay, repreparation of cavity must be done following caries removal and cavity margins are prepared in the tooth structure. This procedure then leads to substantial reduction in tooth structure because the whole cavity has to be prepared without any undercuts. In addition, subgingival location of the preparation margin that frequently occurs in such preparations makes impression taking or moisture control for cementation more difficult.

Compared to cast metal restorations, indirect restorative procedures require removal of large amounts of tooth substance due to the basic requirements of resistance form and convenience form. To minimize the sacrifice of tooth structure, a previous report proposed a technique whereby part of the cavity margin of an amalgam restoration was placed in a glass ionomer cement cavity base used to seal the dentin surface after caries removal ${ }^{4)}$. Moreover, another study reported that the placement of preparation margins in a resin composite base minimized microleakage and enhanced adaptation of all-ceramic crowns $^{5}$. It was thus clear that preparation of the entire cavity in adhesive cavity bases could effectively prevent excessive tooth reduction in indirect restorations.

With tooth-colored crown restorations, stress distribution is a subject that has been extensively investigated using the finite element $\operatorname{method}^{6-12}$. In the same vein, stress analysis has also been performed on inlay/onlay restorations ${ }^{13-16}$. In essence, these studies primarily discussed the stress generated in the restoratives, and the finite element models in these studies were designed according to the conventional technique, i.e., the entire cavity wall consisted of natural tooth structure without a cavity base. Hence, to the best of our knowledge, no stress analysis has examined indirect restorations in which the entire cavity is prepared in cavity bases.

The purpose of the present study, therefore, was to analyze the stress distribution in indirectly restored teeth of which the restorations were prepared with several cavity bases.

\section{MATERIALS AND METHODS}

Determination of elastic modulus and Poisson's ratio To determine the conditions for finite element stress analysis, the elastic moduli of 18 restorative materials (five ceramics, four restorative resin composites, one core resin composite, three flowable resin 
Table 1 Materials used for elastic modulus measurement and their moduli in GPa

\begin{tabular}{|c|c|c|c|c|}
\hline Material & Commercial name & Manufacturer & Lot no. & Elastic modulus \\
\hline Enamel & - & - & - & $132 \leftarrow$ \\
\hline Dentin & - & - & & $40 \leftarrow$ \\
\hline \multirow[t]{5}{*}{ Ceramic } & Ceraeste & Tokuyama Dental, Tokyo, Japan & $\mathrm{C} 050341$ & $155 \leftarrow$ \\
\hline & $\mathrm{OCC}$ & Olympus Optical Co., Tokyo, Japan & 983005 & 102 \\
\hline & Finesse & Dentsply Ceramco, Six Terri Lane Burlington, NJ, USA & 180399 & 102 \\
\hline & IPS Empress & Ivoclar Vivadent, Schaan, Liechtenstein & 700647 & 95 \\
\hline & IPS Empress 2 & Ivoclar Vivadent, Schaan, Liechtenstein & D61356 & 145 \\
\hline \multirow[t]{4}{*}{ Restorative resin composite } & Herculite XRV (heat)** & SDS/Kerr, Orange, CA, USA & 305852 & $30 \leftarrow$ \\
\hline & Herculite XRV & SDS/Kerr, Orange, CA, USA & 305852 & $28 \leftarrow$ \\
\hline & Clearfil AP-X & Kuraray Medical, Tokyo, Japan & 510 & 34 \\
\hline & Filtek P60 & 3M ESPE, St. Paul, MN, USA & $1 \mathrm{KL}$ & 33 \\
\hline Core resin composite & Clearfil DC Core & Kuraray Medical, Tokyo, Japan & UNI: 0198, CAT: 0120 & $35 \leftarrow$ \\
\hline \multirow[t]{3}{*}{ Flowable resin composite } & Revolution Formula 2 & SDS/Kerr, Orange, CA, USA & 309066 & $13 \leftarrow$ \\
\hline & Unifil Flow & GC, Tokyo, Japan & 310141 & 19 \\
\hline & Filtek Flow & 3M ESPE, St. Paul, MN, USA & $3 \mathrm{AA}$ & 19 \\
\hline \multirow[t]{3}{*}{ Resin composite cement } & Nexus 2 & SDS/Kerr, Orange, CA, USA & 308D62 & $19 \leftarrow$ \\
\hline & Bistite II & Tokuyama Dental, Tokyo, Japan & A15434 & 26 \\
\hline & Panavia F 2.0 & Kuraray Medical, Tokyo, Japan & A: $00215 A, B: 00121 A$ & 24 \\
\hline RMGIC* $^{*}$ & Fuji II LC EM & GC, Tokyo, Japan & P: 0202221, L: 0209161 & 41 \\
\hline Glass ionomer cement & Fuji IX GP & GC, Tokyo, Japan & P: 0301291, L: 0310271 & 69 \\
\hline
\end{tabular}

${ }^{*}$ Resin-modified glass ionomer cement. ${ }^{* *}$ The composite was cured with light and heat.

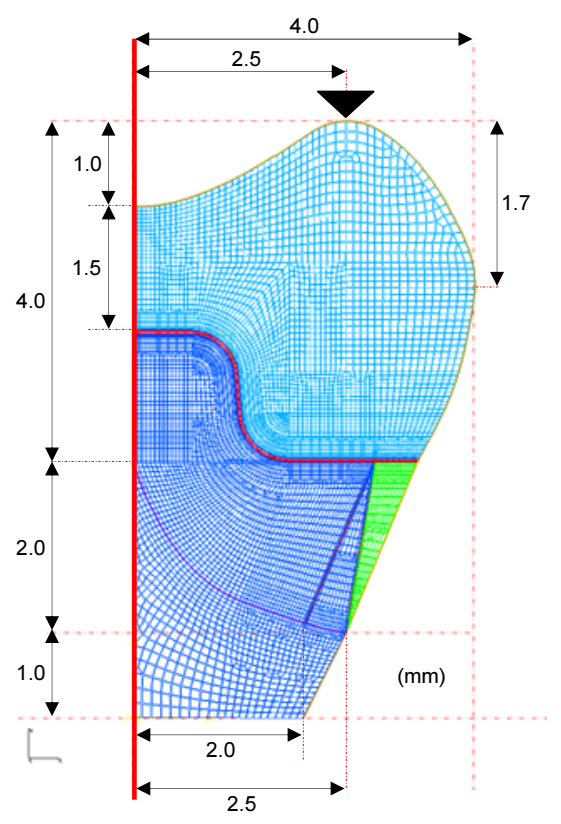

Fig. 1 Dimensions of the axisymmetric mesh model for stress analysis. The axiopulpal and axiogingival line angles are rounded $(r=0.5)$. Taper angle of the axial wall is 5 degrees. Load is applied on the cusp tip (triangle).

composites, three resin composite cements, one resinmodified glass ionomer cement, and one glass ionomer cement), human enamel and dentin were measured by nanoindentation technique using a nanoindentor (ENT-1100A, Elionix, Tokyo, Japan) ${ }^{17-19}$. Three cylindrical specimens $(\varnothing 5 \mathrm{~mm} \times 4 \mathrm{~mm})$ were prepared for each material and sectioned into halves using a low-speed diamond saw. Sections of the restorative materials were then wet-polished through 1- $\mu \mathrm{m}$ diamond paste. As for the tooth sections, the crowns of three human molars were sectioned approximately parallel to the respective occlusal surface, whereby exposed dentin surfaces surrounded by enamel were wet-polished.

Polished sections were subjected to an indentation test. Ten indents were made on each section at a load of $0.005 \mathrm{~N}$. Table 1 lists the measured materials and their elastic moduli, and values indicated by arrows were adopted for stress analysis. As for the Poisson's ratios of the materials, including the tooth substances, they were fixed as 0.3 .

\section{Finite element stress analysis}

An axisymmetric finite element model was designed for a premolar restored with an onlay (Fig. 1). The mesh model consisted of 7947 nodes and 7842 elements. Dimensions of the model were determined by referencing an artificial tooth (No. B3 DA. 3, Nissin, Kyoto, Japan). Figure 2 shows the six models (Models 1-6) developed using combinations of two onlay materials and three resin composites for the cavity base. The cavity base materials in the six models were as follows-Model 1: no cavity base; Model 2: restorative resin composite; Model 3: core resin composite and a flowable resin composite; Model 4: core resin composite and a flowable resin composite; Model 5: flowable resin composite; and Model 6: flowable resin composite. The difference between Models 3 and 4 was in the area of the two resin composites. As for conditions common among the six models, they were namely: thickness of resin composite cement at $50 \mu \mathrm{m}$; pulp chamber and periodontal tissues were ignored; and the materials, including the tooth substrate, were assumed to be homogeneous, isotropic, linearly elastic, and perfectly bonded $^{6,7}$.

A vertical load of $95.5 \mathrm{~N}$ was applied at three 


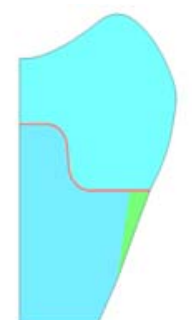

Model 1

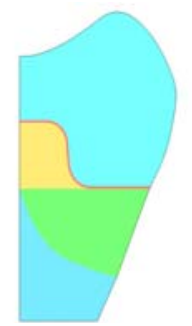

Model 4

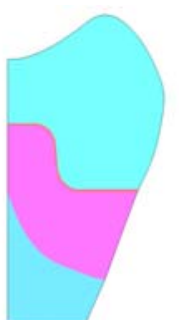

Model 2

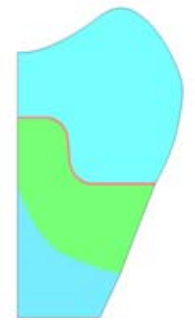

Model 5

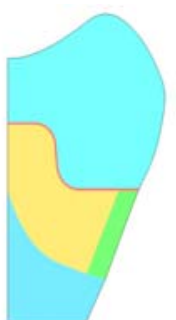

Model 3

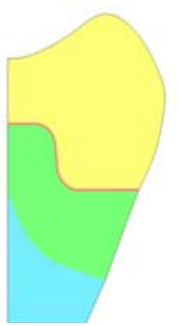

Model 6
Restorative Material

: Ceramic

: Indirect Resin Composite

—: Resin Composite Cement

\section{Cavity Base Material \\ : Restorative Resin Composite \\ : Core Resin Composite \\ : Flowable Resin Composite}

\section{Tooth Substance}

: Enamel

: Dentin

Fig. 2 Six models designed for stress analysis.

nodes $(0.25 \mathrm{~mm}$ in width) on the cusp tip at a distance of $2.5 \mathrm{~mm}$ from the vertical axis (a large triangle shown in Fig. 1) under the assumption that a total occlusal load of $600 \mathrm{~N}^{7,9,20)}$ was applied along the cusp. In an axisymmetric stress analysis, load is generally determined with per radian calculations. Stress analysis was then performed using a finite element analysis software (I-DEAS 10 NX Series m1, UGS Corporation, TX, USA), whereby the distributions and values of tensile stresses among the six models were compared. In addition, the directions of tensile stresses higher than 9.55 $\mathrm{MPa}$ under the load of $95.5 \mathrm{~N}$ were also evaluated with the models revealing relatively high tensile stresses.

\section{RESULTS}

Figure 3 shows the color contours revealed by FEA and the values of tensile stresses. Tensile stresses were generated near the ceramic-cement or resin composite-dentin interface in the six models. In Models $1-3$ and 6 , tensile stress was recognized at one location, whereas in Models 4 and 5, tensile stresses were recognized at two locations. The locations were as follows: with Models 1-3, it was in ceramic close to the axiopulpal line angle; with Models 4 and 5, it was in ceramic close to the axiopulpal line angle as well as in dentin near the gingival margin; with Model 6, it was in dentin near the gingival margin.

Among Models $1-5$ (i.e., ceramic onlay restorations), lowest tensile stress was observed in Model 1, in which the onlay was supported by tooth substances. Tensile stress increased when the tooth substances were replaced with resin composites. Among Models 2-5, the stress in Model 2 was slightly higher than that in Model 3, and the highest stress value was observed in Model 5 in which the cavity base was flowable resin composite only. In Models 4 and 5, whereby tensile stresses were recognized at two locations, the stress in dentin was lower than that in ceramic.

In Model 6 (i.e., resin composite onlay restoration), tensile stress was observed to be generated in the cervical dentin, but not around the axiopulpal line angle. The tensile stress was slightly higher than that in Model 5, although both cavity base materials were the same.

Directions of stresses were analyzed using Models 5 and 6, whereby the highest tensile stresses were recognized at the ceramic near the axiopulpal line angle and at the cervical dentin, respectively. Arrows in Fig. 4 show the directions of stresses exceeding $9.55 \mathrm{MPa}$ in two locations, with Model 5 on the left and Model 6 on the right. Stress directions in both locations were similar, being parallel to the interface of ceramic-cement or resin compositedentin.

\section{DISCUSSION}

Many previous FEA studies have used elastic moduli measured under diverse and varied conditions. However, the value of elastic modulus is easily affected by measurement conditions. Knowledge of elastic moduli is essential to a FEA study, and the use of moduli measured under the same conditions and with the same method is more appropriate for FEA. In the present study, the elastic moduli used were measured under the same conditions. On this note, results of the present FEA study could be 


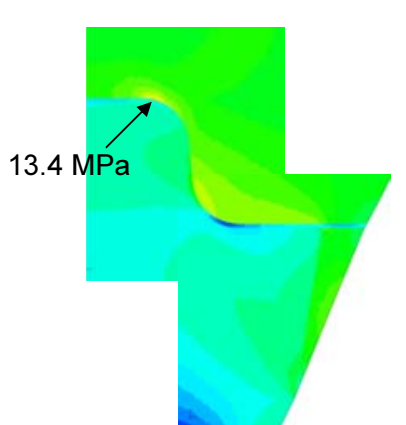

Model 1

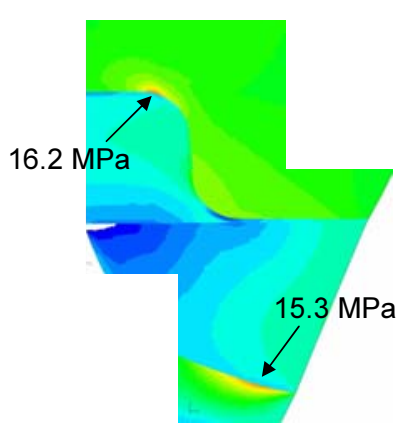

Model 4

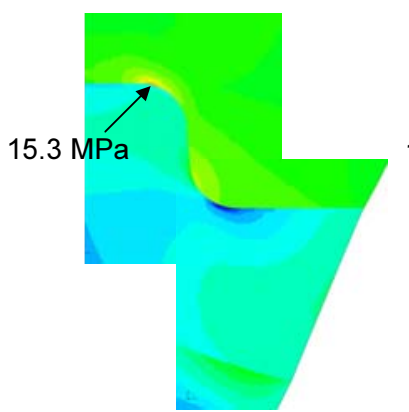

Model 2

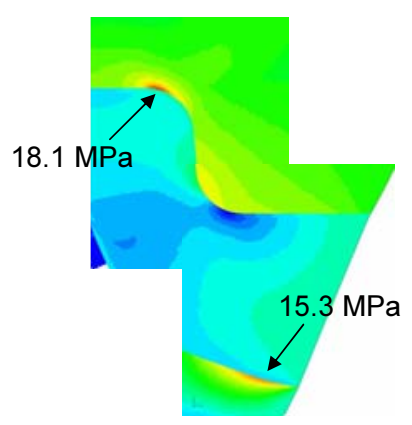

Model 5

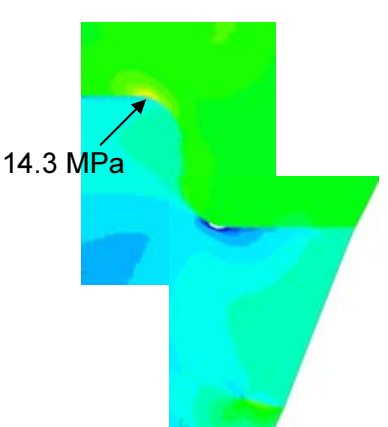

Model 3

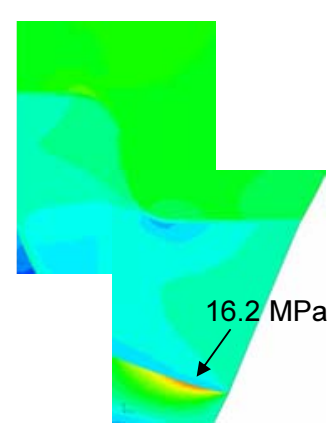

Model 6

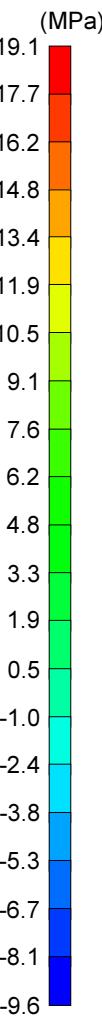

Fig. 3 Distributions of tensile stresses in the six models. Values given indicate the magnitudes of tensile stress at the load of $95.5 \mathrm{~N}$. Colors closer to red in the color guide bar indicate higher tensile stress values.

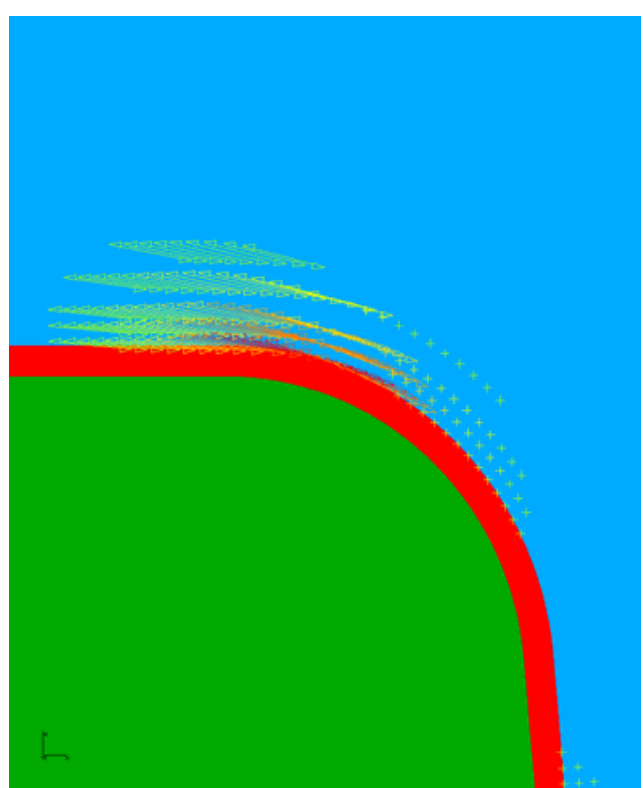

Model 5

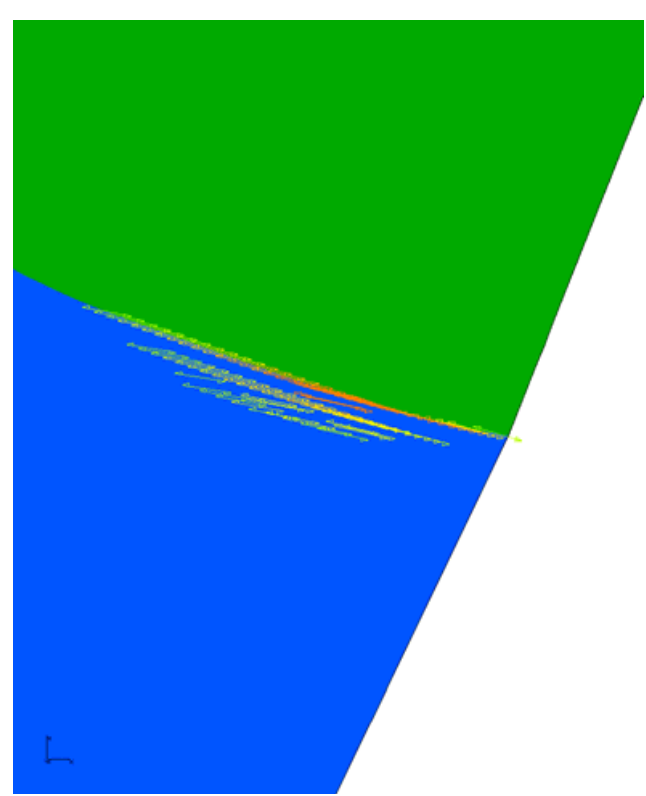

Model 6

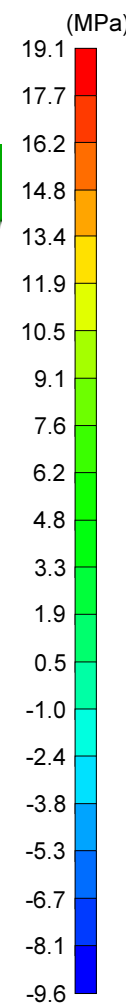

Fig. 4 Directions of tensile stresses above $9.55 \mathrm{MPa}$ in Models 5 and 6. Drawings of Model 5 (left) and Model 6 (right) are near the axiopulpal line angle and gingival margin, respectively. Color of arrow $(\leftrightarrow)$ closer to red in the color guide bar indicates higher tensile stress value. 
considered to be reliable.

Prior to FEA, elastic modulus measurements were performed for 20 materials, including the tooth substances. Out of the 20 moduli, eight were selected for FEA. When a multilayer specimen is loaded, the apparent tensile stresses are generally yielded near the interfaces between the contacting materials and then spread to the material with a higher elastic modulus. Tensile stress increases as the difference between the moduli of the contacting materials becomes larger ${ }^{10)}$. Based on these considerations, eight moduli were selected in order to simulate severe conditions to reveal the higher tensile stresses.

The Poisson's ratios of the materials were fixed as 0.3 , because the ratios of the materials in the present study were estimated to range from 0.2 to $0.4^{21)}$. Moreover, only a slight variation in FEA results are expected if the ratios of the materials vary within this range $^{22)}$.

Obvious tensile stresses common to the five ceramic restorations (Models $1-5$ ) were found near the internal surfaces of the ceramic onlays. This result agreed with a previous fractographic observation of clinically failed glass-ceramic crowns by Kelly et $a ._{.}{ }^{23)}$. They stated that crack initiation sites were located at the internal surfaces of failed crowns. When the ceramic onlay was supported by tooth substances (Model 1), the generated tensile stress was the lowest because the elastic moduli of the tooth substances were higher than those of the resin composite materials evaluated in the present study (Table 1). Among the three resin composites used for the cavity base, the order of elastic moduli was flowable < restorative < core. Therefore, the tensile stress of Model 2 was lower than that of Model 5. Comparing Models 3-5, whereby the cavity base materials were flowable resin composite and/or core resin composite, tensile stress increased as the area of flowable resin composite became larger. In addition, in Models 4 and 5, tensile stress was also generated in the dentin near the flowable composite-dentin interface, whereby the flowable resin composite constituted the majority of the cavity base.

With resin composite onlay restoration (Model 6), distribution of the obvious tensile stresses was different from those in the ceramic restorations. Stress was not observed in the resin composite onlay near the onlay-base interface, because the difference in elastic modulus between the onlay and cavity base was smaller than those in Models 1-5. These findings supported the results of a previous investigation, whereby loads at fracture of all-ceramic crowns were measured when the crowns were supported by resins having different elastic moduli ${ }^{24)}$. It was found that the fracture load of the crown increased markedly with increase in the modulus of the supporting resin.
Maximum tensile stress yielded near the ceramiccement interface in the ceramic onlay (Model 5) was 18.1 MPa. Peters et al. ${ }^{15)}$ stated that crack initiation started from the internal surface of the ceramic inlay when $55-60 \%$ of the load needed for complete fracture was applied to the inlay. Assuming that the tensile strength of dental ceramic was $70 \mathrm{MPa}^{11,25)}$, 55\% of this tensile strength (38.5 MPa) was higher than the maximum tensile stress. Taken together, the ceramic restorative was considered to be resistant to fracture by occlusal loading with the ceramic-cement interface intact. However, when discussing tensile stresses near an adhesive interface, two other major factors should be taken into account: polymerization shrinkage stress of adhesive material ${ }^{22,26,27)}$ and bond strength. Rees and Jacobsen ${ }^{14)}$ reported that a tensile stress of $6.2 \mathrm{MPa}$ was yielded near a ceramic inlaycement interface due to shrinkage of cement with a thickness of $100 \mu \mathrm{m}$. In the context of the present analysis, the shrinkage stress should be lower because of the smaller thickness $(50 \mu \mathrm{m})$. Therefore, the assumed total tensile stress was lower than 25 $\mathrm{MPa}$ near the ceramic-cement interface. To decrease tensile stress and obtain a better prognosis of a restored tooth, cavity base materials with higher elastic moduli appeared to be more suitable for ceramic restorations.

Tensile stress found near the interface was considered to act as a shear stress at the interface because of stress directions (Fig. 4). However, it would be out of scope and out of context to mention delamination since the present study was performed with an assumption of perfect bonding. On this matter, a three-dimensional finite element contact analysis $^{27)}$ would be aptly competent to discuss about delamination - with reference to interlayer bond strength-between contacting materials.

As for the maximum stress in dentin, 16.2 MPa was generated near the flowable composite-dentin interface (Model 6). Hübsch et al. ${ }^{22)}$ reported that the magnitude of tensile stress reached approximately 5 $\mathrm{MPa}$ at the cavity floor of a Class I resin composite filling. Therefore, it might be appropriate to estimate that the maximum tensile stress near the flowable composite-dentin interface was $22 \mathrm{MPa}$. This stress was also considered to produce an interfacial shear stress, similar to the stress in the ceramic near the ceramic-cement interface.

Comparing resin composites versus glass ionomer cements - including resin-modified glass ionomer cements - as cavity base materials, the latter was revealed to have a higher elastic modulus (Table 1 ). Therefore, if both glass ionomer cement and resin composite were equally efficient in bonding to restorative and tooth, tensile stress yielded by glass ionomer would be lower. However, resin composites generally show higher bond strengths. On this 
controversy, Grisanti et $a l^{28)}$ stated that the failure loads of human enamel supported by a bonded resin composite, a resin-modified glass ionomer cement, and a conventional glass ionomer cement were not significantly different. The effect of support was presumed to have been enhanced owing to the bonding efficiency. Nonetheless, in terms of comparison verdict, adhesive resin composites with a higher elastic modulus - such as core resin composites-were thought to be more suitable than glass ionomer cements as cavity base materials.

It should be noted that some properties of dental restoratives deteriorate upon exposure to several types of stress in the oral environment. To have a deeper and more thorough understanding of stress distribution in restorations without excessive tooth reduction, subsequent stress analysis should be performed using mechanical data of deteriorated restorations.

\section{CONCLUSION}

Based on the results of the present study, the tensile stress generated in the tooth restored indirectly without excessive tooth reduction was concluded to decrease as the elastic modulus of the cavity base material increased.

\section{REFERENCES}

1) Fusayama T. New concepts in operative dentistry: Differentiating two layers of carious dentin and using an adhesive resin, Quintessence Publishing Co. Inc., Tokyo, 1980, p.79-156.

2) Tyas MJ, Anusavice KJ, Frenken JE, Mount GJ. Minimal intervention dentistry - A review. FDI Commission Project 1-97. Int Dent J 2000; 50:1-12.

3) Mount GJ, Ngo H. Minimal intervention: A new concept for operative dentistry. Quint Int 2000; 31:527533.

4) Mount GJ, Ngo H. Minimal intervention: Advanced lesions. Quint Int 2000; 31:621-629.

5) Kazama R, Fukushima M, Iwaku M. Marginal leakage and adaptation of CEREC 2 all-ceramic crowns. Japan J Conserv Dent 2003; 46:818-827.

6) Hojjatie B, Anusavice KJ. Three-dimensional finite element analysis of glass-ceramic dental crowns. J Biomech 1990; 23: 1157-1166.

7) Anusavice KJ, Hojjatie B. Tensile stress in glassceramic crowns: Effect of flaws and cement voids. Int J Prosthodont 1992; 5:351-358.

8) Nakamura $T$, Imanishi A, Kashima H, Ohyama $T$, Ishigaki S. Stress analysis of metal-free polymer crowns using the three-dimensional finite element method. Int J Prosthodont 2001; 14:401-405.

9) Proos KA, Swain MV, Ironside J, Steven GP. Finite element analysis studies of an all-ceramic crown on a first premolar. Int J Prosthodont 2002; 15:404-412.

10) Yamamoto $M$, Matsui $T$, Murakami $H$, Kimura $K$, Niwa K, Ito Y. Stress distribution analysis of all ceramic crown in chewing food-Noticed diopside.
Aichi-Gakuin Dent Sci 2002; 40:373-380.

11) Proos KA, Swain MV, Ironside J, Steven GP. Influence of cement on a restored crown of a first premolar using finite element analysis. Int $\mathrm{J}$ Prosthodont 2003; 16:82-90.

12) Proos KA, Swain MV, Ironside J, Steven GP. Influence of core thickness on a restored crown of a first premolar using finite element analysis. Int $\mathrm{J}$ Prosthodont 2003; 16:474-480.

13) Dérand T. Stress analysis of cemented or resinbonded loaded porcelain inlays. Dent Mater 1991; 7:21-24.

14) Rees JS, Jacobsen PH. Stresses generated by luting resins during cementation of composite and ceramic inlays. J Oral Rehab 1992; 19:115-122.

15) Peters MCRB, De Vree JHP, Brekelmans WAM. Distributed crack analysis of ceramic inlays. J Dent Res 1993; 72:1537-1542.

16) Abu-Hassan MI, Abu-Hammad OA, Harrison A. Stress distribution associated with loaded ceramic onlay restorations with different designs of marginal preparation. An FEA study. J Oral Rehab 2000; 27:294-298.

17) Oliver WC, Pharr GM. An improved technique for determining hardness and elastic modulus using load and displacement sensing indentation experiments. J Mater Res 1992; 7:1564-1583.

18) Willems G, Celis JP, Lambrechts P, Bream M, Vanherle G. Hardness and Young's modulus determined by nanoindentation technique of filler particles of dental restorative materials compared with human enamel. J Biomed Mater Res 1993; 27:747-755.

19) Zheng L, Nakajima M, Higashi T, Foxton RM, Tagami J. Hardness and Young's modulus of transparent dentin associated with aging and carious disease. Dent Mater J 2005; 24:648-653.

20) Tortopidis D, Lyons MF, Baxendale RH, Gilmour WH. The variability of bite force measurement between sessions, in different positions within the dental arch. J Oral Rehab 1998; 25:681-686.

21) O'Brien WJ. Dental materials and their selection, 2nd ed, Quintessence Publishing Co. Inc., Carol Stream, 1997, p.365.

22) Hübsch PF, Middleton J, Knox J. A finite element analysis of the stress at the restoration-tooth interface, comparing inlays and bulk fillings. Biomater 2000; 21:1015-1019.

23) Kelly JR, Campbell SD, Bowen HK. Fracture-surface analysis of dental ceramics. J Prosthet Dent 1989; 62:536-541.

24) Scherrer SS, de Rijk WG. The fracture resistance of all-ceramic crowns on supporting structures with different elastic moduli. Int J Prosthodont 1993; 6:462467.

25) Combe E. Notes on dental materials, Churchill Livingstone, London, 1986, pp.370-371.

26) Davidson CL, Feilzer AJ. Polymerization shrinkage and polymerization shrinkage stress in polymer-based restoratives. J Dent 1997; 25:435-440.

27) Ikeda $\mathrm{T}$, Wakabayashi N, Ona M, Ohyama T. Effects of polymerization shrinkage on the interfacial stress at resin-metal joint in denture-base: A non-linear $\mathrm{FE}$ stress analysis. Dent Mater 2006; 22:413-419.

28) Grisanti LP, Troendle KB, Summit JB. Support of occlusal enamel provided by bonded restorations. Oper Dent 2004; 29:49-53. 